\title{
Malaria may not rise as world warms
}

\section{Studies suggest that strategies to combat the disease are offsetting the impact of climate change.}

Of the many climate-change catastrophes facing humankind, the anticipated spread of infectious tropical diseases is one of the most frequently cited - and most alarming. But a paper in this week's Nature adds to the growing voice of dissent from epidemiologists who challenge the prediction that global warming will fuel a worldwide increase in malaria.

On the surface, the connection between malaria and climate change is intuitive: higher temperatures are known to boost mosquito populations and the frequency with which they bite. And more mosquito bites mean more malaria.

Yet when epidemiologists Peter Gething and Simon Hay of the Malaria Atlas Project at the University of Oxford, UK, and their colleagues compiled data on the incidence of malaria

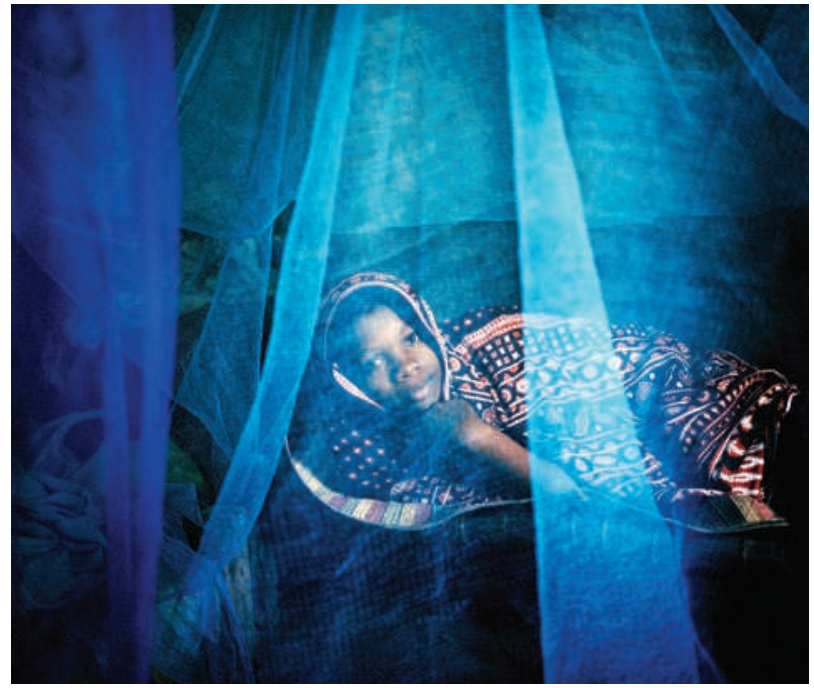

Preventative measures such as the widespread use of bed nets have outweighed the effects of climate warming on malaria. in 1900 and 2007 (see page 342), they found the opposite: despite rising temperatures during the twentieth century, malaria has lost ground. According to the models the researchers used to tease out the factors affecting the incidence of malaria, the impact of public-health measures such as improved medications, widespread insecticide use and bed nets have overwhelmed the influence of climate change. "Malaria is still a huge problem," says Gething. "But climate change per se is not something that should be central to the discussion. The risks have been overstated."

Some earlier analyses painted a dire picture of a malaria-ridden future, 3 but these models often exclusively evaluated the impact of warmer temperatures without taking other factors into consideration, says Paul Reiter, an entomologist at the Pasteur Institute in Paris. The latest assessment of the Intergovernmental Panel on Climate Change noted these concerns: "Despite the known causal links between climate and malaria transmission dynamics, there is still much uncertainty about the potential impact of climate change on malaria at local and global scales."

Gething and colleagues' study is the first of its kind to provide a detailed statistical model of global trends over the twentieth century, but it does have limitations. For instance, the data used to generate a global map of malaria in 1900 sum up all malarial infections, including those by a malaria parasite named Plasmodium vivax, whereas the data in

\section{Pacific tuna population may crash at any time}

Numbers of Pacific bluefin tuna may be about to go the same way as those of their Atlantic cousins. The Pacific population was thought to be the endangered fish's only remaining stronghold. But official reports on stock sizes have overlooked changes to fishing practices that could mean they are heading for a crash, according to recent assessments.

In the Atlantic Ocean and the Mediterranean Sea, fishing has caused tuna populations to fall below $15 \%$ of their historical levels. Even so, an attempt this year to ban trade in the fish failed to gain international approval at a meeting in March of the Convention on International Trade in Endangered Species of Wild Fauna and Flora (see doi:10.1038/news.2010.139).

By contrast, Pacific bluefin (Thunnus orientalis) populations had been thought to be stable, with enough young fish maturing each year to replace those caught. In July 2009, a working group of the International Scientific Committee for Tuna and Tuna-like Species in the North Pacific Ocean (ISC) concluded that recruitment of juveniles to the population "does not appear to have been adversely affected by the relatively high rate of exploitation".

But the working group admitted that a lack of data meant recruitment since 2005 is highly uncertain. And the belief that the stock is stable is based

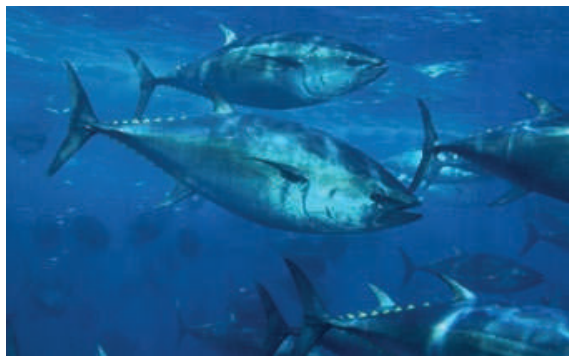

Pacific bluefin tuna are in high demand. says Katsukawa.

The change in fishing practice has gone hand in hand with a growth in the market for juvenile tuna, says ChienChung Hsu, a fisheries biologist at the National Taiwan University in Taipei. Juveniles 10-15 centimetres long fetch US $\$ 100$ on a false assumption that fishing practices have not changed, says Toshio Katsukawa, a fisheries expert at Mie University in Tsu City, Japan. From speaking to fishermen, Katsukawa is most concerned that, in the past few years, boats have begun targeting the tuna's spawning grounds.

This tactic increases catches, simultaneously making the stock seem bigger but damaging the fish's breeding capacity. "If things go on like this, the Pacific [bluefin] populations will be the first to collapse [before the Atlantic stock]," each in Japanese markets, he says. By contrast, adult Pacific bluefins can sell for $\$ 100,000$ or more, and Katsukawa points out that fishermen could make more profit by waiting for the fish to mature. Overall, more than $70 \%$ of the Pacific bluefin catch is taken by fishermen from Japan, where the fish is prized for its use in sushi.

Data from the ISC show that more than $70 \%$ of Pacific bluefin tuna caught today are less than one year old, compared with around $60 \%$ in the 1960s, although Katsukawa believes that even 
the 2007 map track infections by just one malaria parasite, $P$. falciparum, which carries the highest disease burden. And the analysis does not take into account some parameters that are likely to change as a result of global warming, such as rainfall patterns and human migrations.

Nevertheless, the results largely match those of several other recent studies, including one published last year by Kevin Lafferty of the US Geological Survey in Santa Barbara, California, which also concluded that rising temperatures over the last century had no net impact on the incidence of malaria (K. D. Lafferty Ecology 90, $888-900 ; 2009)$. In 2000, models designed by David Rogers and Sarah Randolph at the University of Oxford predicted that although some parts of the world would gain malaria because of climate change, large areas would see a drop in disease due to reductions in rainfall and humidity (D. J. Rogers and S. E. Randolph Science 289, 1763-1766; 2000). The result: no net difference.

"The complexity of malaria and the other vector-borne diseases is astonishing," says Reiter. "To bring it down to just one factor climate change - is totally unjustifiable."

The same could hold true for other diseases that rely on intermediate vectors like mosquitoes. Dengue fever, for example, has also been touted as an infectious disease that could get a boost from climate change. The virus, which is carried by mosquitoes, is already on the march, and is spreading more rapidly into the southern
United States. But the impact it will have there is likely to be minimal compared with that in less developed regions of the world because of lifestyle differences, says Reiter. Americans spend more time indoors, he says, and are more likely to have window screens to keep mosquitoes out.

Laura Harrington, who studies mosquitoborne diseases at Cornell University in Ithaca, New York, agrees. "In the context of vectorborne diseases, climate change is probably going to have a minimal role in comparison to other factors," she says. Even so, Gething's results are likely to be controversial, cautions Richard Ostfeld, a disease ecologist at the Cary Institute of Ecosystem Studies in Millbrook, New York. Although global analyses such as Gething's are useful, he says, they may miss important regional trends - such as the spread of mosquitoes from the lowlands to the highlands of eastern Africa, which some argue is the result of rising temperatures. "There's a pretty strong spatial disconnect between areas where there is strong economic development and increasing control of mosquitoes, versus those areas where the risk of climate-induced disease is highest," he says.

Others worry that the results of the study will be misinterpreted. "On smaller scales, climate change certainly has big effects on disease," says Harrington. "This does not diminish the importance of climate change at all."

Heidi Ledford this increase is an underestimate. More than $90 \%$ of the catch is less than two years old. "The increasing juvenile catch is increasing the risk of population collapse," says Hsu. "The population is dropping for all age classes and we see signs of serious problems if no management measures are set immediately."

Responding to concerns about the health of the stock, Japan's Fisheries Agency last week outlined new measures to monitor and manage the tuna populations. These specify limits on the weight of fish that each boat can catch, restrictions for the large boats using encircling nets that account for most tuna fishing, along with new requirements for other boats to report their catches. And fish farmers, who collect an increasing but unknown number of juveniles and raise them in pens, will be required to register and report their activities. The agency plans to implement the restrictions by April 2011.

The measures also call for better information on juvenile stocks and spawning areas, and for the establishment of an international network of researchers to study and manage Pacific bluefin tuna fisheries. "To protect these spawning regions, we have to find out where they are and when the peak seasons are. Then we can start to make restrictions on which ones can be fished and when they can be fished," says Yukio Takeuchi, a researcher at the National Research Institute of Far Seas Fisheries, an arm of the Fisheries Agency based in Shizuoka, Japan, who chaired the ISC working-group report.

Katsukawa says that the new measures, "if done effectively", could have a major impact. But he fears they will be implemented too slowly to head off an irrecoverable drop. "It could happen suddenly, but we won't see it until it happens." David Cyranoski

\section{Corrections}

The News story 'China and Taiwan strengthen academic ties' (Nature 465, 148-149; 2010) incorrectly stated that Xiao-fan Wang is the first mainland-China-born president of the Society of Chinese Bioscientists in America. In fact, he is the first president to be born, raised and educated under the communist government of the People's Republic of China.

The News Feature 'Life after death' (Nature 465, $150-155 ; 2010$ ) misspelt the name of Debra Moriarity throughout. 